\title{
Assessment of the Effect of Ethanol Extract of Tridax Procumbens (linn.) on Sodium Arsenite-induced Toxicities in Male Wistar Rats
}

\author{
Adeluwoye, Adekunle O. ${ }^{1,2}$, Odunola, Oyeronke A², Gbadegesin, Michael A², \\ Adelabu, Olusegun $0^{2}{ }^{2}$
}

${ }^{1}$ Department of Medical Laboratory Science, Babcock University Teaching Hospital, Ibadan Annex, Babcock

University, Ilishan, Nigeria.

${ }^{2}$ Department of Biochemistry, Cancer Research and Molecular Biology Laboratories, University of Ibadan, Ibadan,

Nigeria.

*Corresponding Author

,Adekunle O. Adeluwoye

${ }^{1}$ Department of Medical Laboratory Science

Babcock University Teaching Hospital

Ibadan Annex

Babcock University

Ilishan, Nigeria.

Phone: +2348035434655,

Email: princekunlzy@gmail.com

Received: 28 April 2017; | Revised: 21 July 2017; | Accepted: 23 August 2017

\begin{abstract}
This study seeks to assess the effect of ethanol extract of Tridax procumbens (linn.) (EETP), a common procumbent plant with several potential therapeutic values, on sodium arsenite-induced toxicities in male wistar rats. Thirty five (35) male wistar rats divided into seven groups of five (5) each, were used. Rats in the pre-treatment, post-treatment and co-administration groups received $200 \mathrm{mg} / \mathrm{Kg}$ body weight of EETP. Sodium arsente treated groups received $1 / 10$ of LD50 i.e. $2.5 \mathrm{mg} / \mathrm{Kg}$ sodium arsenite (SA) both in the cotreated groups and SA alone groups on day 1 and day 14, respectively. Liver enzymes, Alanine aminotransferase (ALT), Aspartate aminotransferase (AST), Gamma glutamate transferase (GGT), and Alkaline Phosphatase (ALP) and other biochemical parameters (Total Bilirubin, Total Protein, Albumin. Total Cholesterol, and Urea) were measured in tissue homogenate to evaluate toxicity in the induced animal model. Nephrotoxicity was assessed using serum creatinine level, while micronucleated polychromatic erythrocytes (mPCE) assessment was carried out for the genotoxicity testing. Statistical analysis using ANOVA and Dunnett's post hoc test was done for all parameters measured. Percentage weight gain was significantly decreased $(\mathrm{p}<0.05)$ in the EETP+SA co-treated groups. There was a significant decrease $(\mathrm{p}<0.05)$ in GGT, AST, and ALT activities in the EETP+SA co-treatment groups when compared with the sodium arsenite-induced groups, in a treatment mode dependent manner with the pre-treatment group
\end{abstract}


showing the most reversal of toxicity. Also, a treatment mode dependent manner of significant decrease $(\mathrm{p}<0.05)$ in level of Total Protein, Urea, and Total cholesterol was observed when compared with both control group and SA treated groups. There was also a significant increase in serum creatinine levels of the EETP, SA, EETP+SA co-treated groups, with the EETP+SA co-treated groups showing a combine effect. The Tridax procumbens co-treated groups show a significant decrease $(\mathrm{p}<0.05)$ in mPCE when compared with the sodium arsenite treated groups. Histopathological studies of tissue sections of liver and kidney done, with congested blood vessels and focal area of inflammation and/or necrosis, corroborated the observed biochemical assays. In sum, the result from this study, in conformity with previous researches, shows that administration of EETP possesses some anti-hepatotoxic and anti-genotoxicity effects. However, the ethanol extract of Tridax procumbens was also shown to possess some level of toxicity, and so specific plant part such as the leaf or flower, and/or fractional extraction of beneficial phytochemical component is recommended.

Abbreviations: EETP - ethanol extract of Tridax procumbens (linn.), SA - sodium arsenite, ALT Alanine aminotransferase, AST - Aspartate aminotransferase, GGT - Gamma glutamate transferase, ALP Alkaline Phosphatase, mPCE - micronucleated polychromatic erythrocytes, NSL - No significant lesion, MC - Moderate congestion, MiS - Focal area of mild steatosis, mPP - moderate periportal inflammation, $\mathbf{Z 2}$ - Inflammation in zone 2, sPP - Slight periportal inflammation, SD - Sinusoidal dilation, NSL - No significant lesion, MC - Moderate congestion, RC - Renal cast, GS - Moderate glomerulosclerosis, G Focal area of tissue granulation, $\mathbf{N}$ - Moderate tissue necrosis, PV - Perivascular inflammation, PT Peritubular inflammation.

Keywords: Toxicities, Tridax procumbens, sodium arsenite, ethanol extract of Tridax procumbens (EETP), nephrotoxicity, genotoxicity, anti-hepatotoxic.

\section{Introduction}

Literature is historically filled with the evidence of plants providing a source of inspiration for novel drug compounds, as well as well-being promoting and health benefiting constituents. Medicinal plants which produce and accumulate constituents, primarily for their own defense, have medical properties ${ }^{[1]}$. Suggestions that oxidative stress play a role in human diseases have led to the proposal that health might be improved by increased dietary intake of antioxidants ${ }^{[2-6]}$ Recent researches is filled with accumulated evidences showing the benefit of enriching the body system with natural antioxidant ${ }^{[7-11]}$, particularly from plant source as nutraceuticals.

Toxicity largely rather than being seen as a single molecular event, can be viewed as a cascade of events that begins with exposure, and proceeding through distribution, metabolism, and ending with interaction with cellular macromolecules (usually
DNA or protein) that results in the expression of a toxic end point ${ }^{[12]}$.

Sodium-arsenite is a toxic chemical compound known to induce cytotoxicity and genotoxicity in many laboratory animal models. A number of studies have proved sodium arsenite to be highly toxic ${ }^{[13-15]}$. It is a chemical whose hepatotoxic and clastogenic effect on laboratory animals has been previously demonstrated in our laboratory by Odunola et al., [16] and Gbadegesin et al., [17]. Sodium arsenite has found a wide use as a component of herbicides, fungicides, insecticides, and algaecides, and in the manufacture of arsenical soap ${ }^{[18-21]}$. Arsenic intoxication has as its principal mechanism, the disruption of thiol proteins [22]. Sodium arsenite has also been shown to decrease glutathione levels and increase lipid peroxidation in liver, kidney and heart ${ }^{[23,24]}$.

Tridax procumbens (Linn.), a common plant found in the tropics ${ }^{[25]}$, which though native to tropical America, but has been introduced to tropical, subtropical, and mid temperate regions 
worldwide, is a procumbent herb that is valued for its pharmaceutical properties ${ }^{[26]}$. According to Ali [27], it has been found to possess significant medicinal properties on blood pressure, bronchial catarrh, malaria, dysentery, diarrhea, stomach ache, headache, wound healing, it also prevents hair fall and check hemorrhage from cuts and bruises. Its flowers and leaves possess antiseptic, insecticidal and parasiticidal properties [26,28]. Suseela et al., [29] also reported that Tridax procumbens is known for several potential therapeutic activities like antiviral, antioxidant antibiotic efficacies, wound healing activity, insecticidal and anti-inflammatory activity. Some reports from tribal areas in India state that the leaf juice can be used to cure fresh wounds, to stop bleeding, as a hair tonic ${ }^{[29]}$. A study by GamboaLeon in the year 2014 proved that a mixture of Tridax procumbens and Allium sativum extracts was a promising natural treatment for cutaneous leishmaniasis and that its healing effects made it a good candidate for a possible new phytomedicine ${ }^{[30]}$. The plant has also been reported to show various pharmacological activities like immunomodulatory, antidiabetic, anti-hepatotoxic and anti-oxidant, anti-inflammatory, analgesic, and marked depressant action on respiration ${ }^{31-}$ 35]. The present study was undertaken to assess the ethanol extract of the Tridax procumbens on sodium arsenite-induced toxicities, in vivo.

\section{Materials and Methods}

\subsection{Chemicals and reagent kits}

All other chemicals used in this research work were of the highest grade and purity. Sodium arsenite $(99.8 \%)$ was purchased from SigmaAldrich (St. Louis, MO, USA), while absolute ethanol (99.8\%) was purchased from British Drug Houses (Dorset, Poole, UK). All other chemicals were obtained either from Sigma-Aldrich (St. Louis, MO, USA), British Drug Houses (Dorset, Poole, UK), or Lab Tech Chemicals (Avighkar). Biochemical assays kits were obtained from Cypress Diagnostics (Langdorp, Belgium).

\subsection{Animals}

Thirty-five male albino rats of wistar strain weighing between $90 \mathrm{~g}$ and $116 \mathrm{~g}$ were obtained from the Central Animal House, College of Medicine, University of Ibadan, Nigeria. The animals divided into seven groups of five animals each, kept in a plastic suspended cage, were housed in the experimental facility of Biochemistry Department, a well-ventilated animal house, under standard environmental conditions (12 hours light/dark cycle). The animals were fed with standard rat pellets and water ad libitum throughout the period of acclimatization and administration of the test compounds. All animals were handled humanely in conformity with the University of Ibadan ethical guideline for the care and use of laboratory animals, following approval.

\subsection{Plant Materials and Preparation of Crude Extract}

Fresh plant samples of Tridax procumbens were collected from the residential area of the University College Hospital, Ibadan, Oyo State, Nigeria. The specimen was authenticated by the Herbarium coordinator of the Botany Department, University of Ibadan, Oyo state, Mr Donatus. The plant sample were rinsed in running tap water and air dried at room temperature for $10-15$ days. It was later powdered by using an electric blender (Omega BL330S). This powder (700g) was then extracted using the cold method of extraction for 72hours with $97 \%$ ethanol (absolute). Collected solutions were filtered through muslin clothe before filtering using Whatman No-1 filter paper. The extracts were evaporated to dryness under reduced pressure at $90^{\circ} \mathrm{C}$ by Rotary vacuum evaporator to obtain the concentrated extract and stored in a freeze condition at $-18^{\circ} \mathrm{C}$ until used for further analysis. A yield of $23.6 \mathrm{~g}$ representing $3.37 \%$ was obtained upon concentration of the extract.

\subsection{Phytochemical analysis}

Screening for major phytochemical constituents which includes tannins, flavonoids, terpenoids, glycosides, saponins, alkaloids, oxalate, phytates, steroids, phlobatannins, carotenoids, cyanides, and anthraquinones was undertaken using 
standard chemical test procedures as described by Marcano and Hasenawa, ${ }^{[36]}$ and Tiwari, et al., ${ }^{[37]}$.

\subsection{Experimental design}

The animals were randomly divided into seven groups of five animals each as designated below, and acclimatized for 14 days on commercial rat pellet before treatment with test substances for the next 14 days as described.

Group 1 - Control (Distilled water) group

Group 2 - Ethanol extract of Tridax procumbens (EETP) treated group

Group 3 - Group treated with Sodium arsenite on day 14 only

Group 4 - Group treated with Sodium arsenite on day 1 only

Group 5 - Group pre-treated with EETP for 14 days prior to treatment with sodium arsenite on Day 14 Group 6 - Group treated with sodium arsenite on day1 prior to post-treatment with EETP for 14 days

Group 7 - co-administration group treated with sodium arsenite and EETP for 14 days

The control group animals were allowed food and water ad libitum, while the extract alone group (EETP) received $200 \mathrm{mg} / \mathrm{Kg}$ body weight of ethanol extract of Tridax procumbens for 14 days. The sodium arsenite alone treated groups received 1/10 of LD50 i.e. $2.5 \mathrm{mg} / \mathrm{Kg}$ body weight of sodium arsenite on day 1 (SA-Day 1) and day 14 (SA-Day 14), respectively. The co-treatment groups which include the pre-treatment group (SA+EETP pretreated), post-treatment (SA+EETP post-treated), and co-administration group (SA+EETP co-admin.) received $200 \mathrm{mg} / \mathrm{Kg}$ body weight (bw) EETP for 14 days either before, after, or as co-administration with $2.5 \mathrm{mg} / \mathrm{Kg}$ bw of sodium arsenite. At the end of the treatment period the rats were weighed, and were sacrificed by cervical dislocation sequel to collection of blood into heparinized bottle from the orbital plexus using heparinized microhaematocrit capillary tubes.

\subsection{Organ weight measurement and clinical chemistry analysis}

The liver and kidneys of the animals were surgically removed, rinsed with ice cold physiological saline, blotted dry and weighed. The percentage weight, and also the relative organ weight of the liver and kidney were determined. Sequel to the measurement of the liver, kidney and testicular organs, the liver from each rat was separately homogenized in a volume of the homogenizing buffer (ice-cold Phosphate buffer, $0.1 \mathrm{M}, \mathrm{pH} 7.4$ ) four times of its weight, using a Teflon homogenizer. The homogenizing buffer was prepared by dissolving $0.496 \mathrm{~g}$ of di-potassium hydrogen orthophosphate, K2HPO4 and $0.973 \mathrm{~g}$ of potassium di-hydrogen orthophosphate, KH2PO4 in $9 \mathrm{ml}$ of distilled water. The $\mathrm{pH}$ was adjusted to 7.4 and then made up to a $100 \mathrm{ml}$ with distilled water. The resulting homogenate in each case was centrifuged at 10,000g for 10 minutes in a Thermo Scientific WX Ultra 100 centrifuge at 40C to obtain the post mitochondrial fraction. The resultant supernatant was collected and used for different biochemical analyses. Storage was done under $0 \mathrm{oC}$ to $4 \mathrm{oC}$ to preserve enzyme activity.

\subsection{Liver enzyme biomarkers and biochemical markers analysis}

Liver enzymes including activity alanine aminotransferase (ALT), aspartate aminotransferase (AST), gamma glutamyltransferase (GGT) and alkaline phosphates (ALP) were measured using Cypress Diagnostic (Langdorp, Belgium) commercial laboratory kits. Similarly, total protein, albumin, urea, total bilirubin and total cholesterol as functional biochemical marker for hepatotoxicity, and creatinine as a marker for nephrotoxicity were assessed using laboratory kits obtained from Cypress Diagnostic (Langdorp, Belgium). The absorbance of the tests were measured by spectrophotometric method using Spectrumlab 752s UV VIS.

\subsection{Histopathological analysis}

The right lobe of the liver and the left kidney from treated and control animals were cut to obtain tissue slice and fixed in $10 \%$ formal saline. Following fixation, organs were processed by passing through ascending grade of alcohol-water concentrations to dehydrate, cleared in xylene and subsequently embedded in paraffin wax blocks. 
Using rotary microtome, tissue sections of $3-5 \mu \mathrm{m}$ thick were cut, stained with Haematoxylin-eosin $(\mathrm{H}-\mathrm{E})$, and then mounted using neutral dibutylphthalate xylene (DPX) medium for microscopic examination at $\mathrm{x} 400$ magnification.

\subsection{Statistical analysis}

All statistical analyses were conducted with GraphPad prism 6.0® computer programs. Data are presented as mean \pm SE $(n=5)$. One way ANOVA was used to determine the differences among various groups. Dunnett post-hoc multiple comparison procedure was done for comparisons between treated groups and corresponding negative control when the corresponding $F$ test for differences among the treated group means was significant pair wise. Differences were considered significant at $\mathrm{p}<0.05$ level of significance.

\section{Results and Discussion}

This study was designed to assess the biological effect of Tridax procumbens on toxicities induced by sodium arsenite in male wistar rats. Photochemical components, though naturally occurring plant chemicals providing it with colour, odour and flavor, have been shown by research to influence the chemical processes inside the human bodies, mostly in helpful ways ${ }^{[38]}$. Significant physiological effects, be it as antioxidants, stimulation of enzymes, hormones mimicking, interference with DNA replication, destruction of bacteria, or curbing of the onset of diseases such as cancer and heart disease, are a number biological effects exerted by phytochemicals in the body.

In this study, the preliminary phytochemical study shows that Tridax procumbens is abundantly composed of a variety of phytochemical components (Figure1a and Figure 1b). This is as confirmed by previous studies by Ikewuchi et al., ${ }^{[39}$ which reported the presence of alkaloids, carotenoids, flavonoids, flavones, catechin, saponins and tannins.

The result of the percentage body weight gain and relative weights of liver and kidney of the experimental animals were assessed. It has been reported that increase or decrease in either absolute or relative weight of an organ after administering a chemical or drug is an indication of the toxic effect of that chemical ${ }^{[40]}$. The result from this study (Table 1) shows a significant decrease $(p<0.05)$ in relative weight of the kidney of only the pre-treated group, while for the relative liver weight, a decrease, but a non-significant one $(\mathrm{p}<0.05)$ was observed in all the groups. These decreases were however reversed by EETP $(200 \mathrm{mg} / \mathrm{kg})$, though not significantly. Also, a significant decrease was observed in the percentage body weight of the three SA+EETP co-treated groups with the coadministration of sodium arsenite as toxicant with concurrent administration of Tridax procumbens causing a markedly reduced percentage body weight in the co-administration group, perhaps due to prolonged combined exposure (Figure 2).

Table 1: Effect of ethanol extract of Tridax procumbens on relative liver and kidney weight of treated rats.

\begin{tabular}{c|c|cc}
\hline \multicolumn{2}{c|}{ Experimental Groups } & $\begin{array}{c}\text { Relative Liver weight } \\
(\boldsymbol{\%})\end{array}$ & $\begin{array}{c}\text { Relative Kidney weight } \\
(\boldsymbol{\%})\end{array}$ \\
\hline Control (D/W) & $\mathbf{1}$ & $4.08 \pm 0.14$ & $0.73 \pm 0.02$ \\
EETP & $\mathbf{2}$ & $4.20 \pm 0.21$ & $0.74 \pm 0.06$ \\
SA Day-14 & $\mathbf{3}$ & $3.94 \pm 0.15$ & $0.69 \pm 0.03$ \\
SA Day-1 & $\mathbf{4}$ & $3.59 \pm 0.31$ & $0.63 \pm 0.05$ \\
SA + EETP pre-treated & $\mathbf{5}$ & $4.08 \pm 0.12$ & $0.58 \pm 0.03 *$ \\
SA + EETP post-treated & $\mathbf{6}$ & $3.99 \pm 0.34$ & $0.63 \pm 0.03$ \\
SA + EETP co-administration & $\mathbf{7}$ & $3.57 \pm 0.33$ & $0.76 \pm 0.05$ \\
\hline
\end{tabular}

Values are Mean \pm SEM; $* \mathrm{p}<0.05$ compared to Control. 


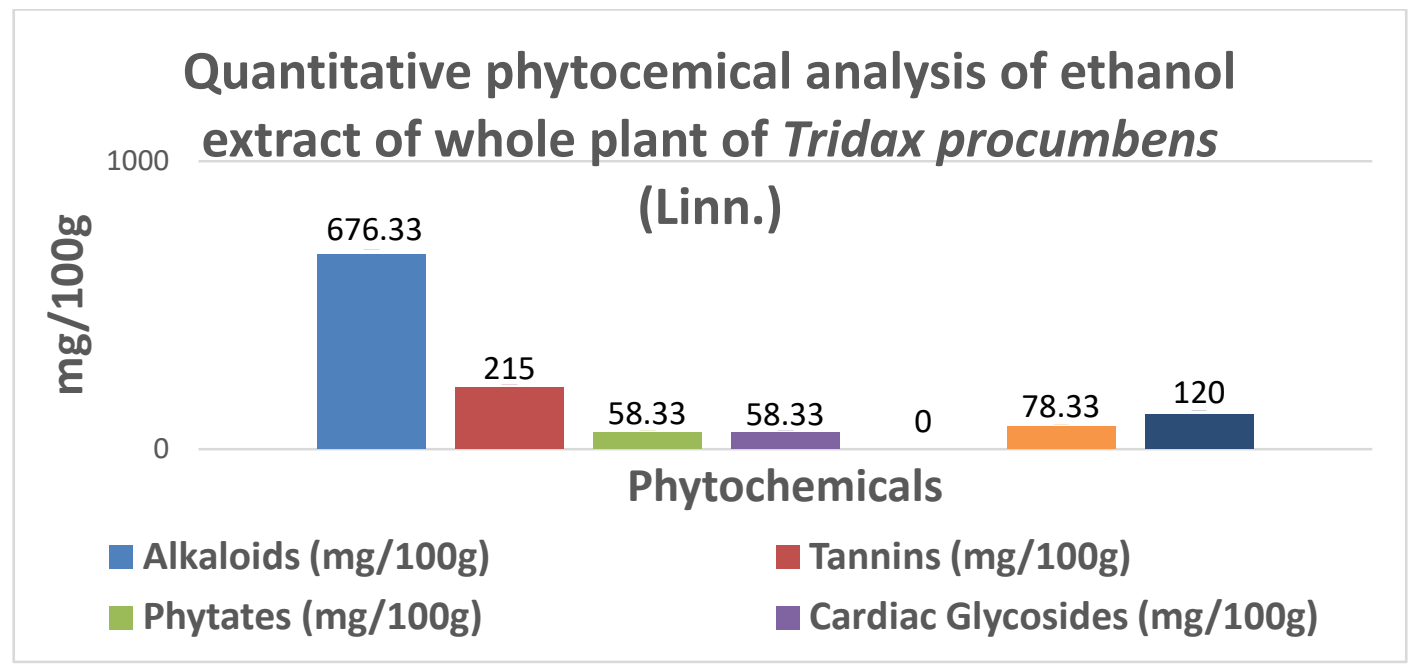

Figure 1a: Quantitative phytochemical analysis of ethanol extract of Tridax procumbens (Linn.)Values are Mean \pm $\mathrm{SD},(\mathrm{n}=3)$.

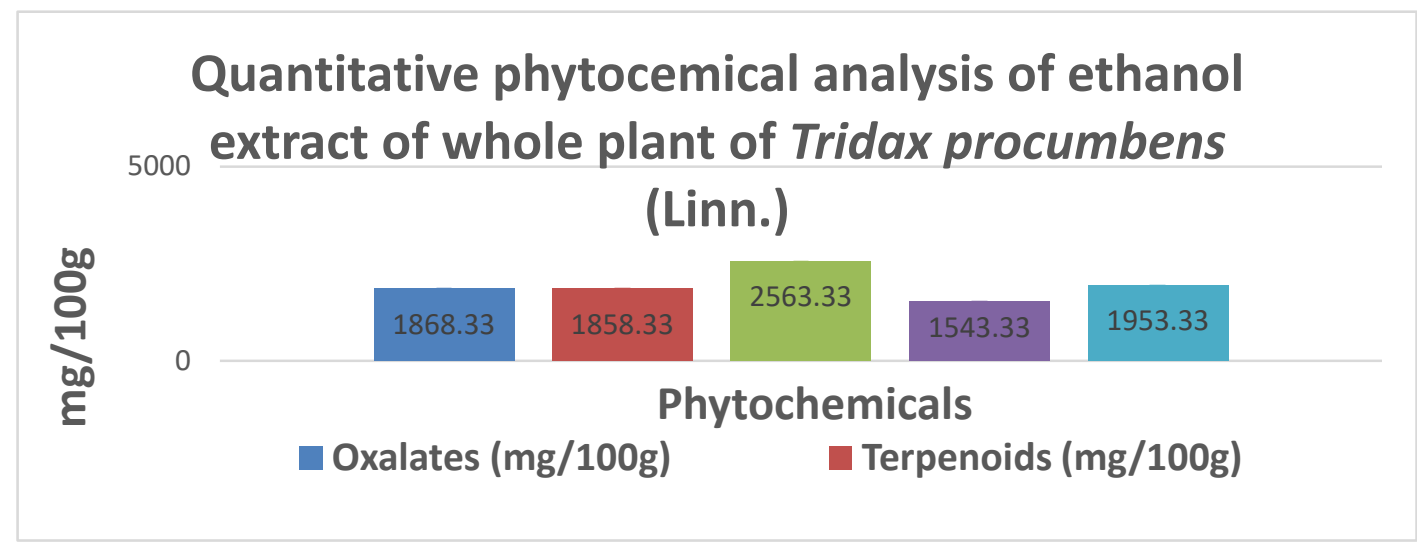

Figure 1b: Quantitative phytochemical analysis of ethanol extract of Tridax procumbens (Linn.) Values are Mean \pm $\mathrm{SD},(\mathrm{n}=3)$

Liver enzymes levels are usually raised in acute hepatoxicity, but tend to decrease with prolonged intoxication due to damage to the liver ${ }^{41]}$. ALT is an enzyme found in the liver that helps the body metabolize protein. When the liver is damaged, ALT is released into the bloodstream and levels increase. The graded reduction in the liver homogenate levels could be an indication of structural damage to the hepatic tissue. The result of liver enzyme biomarkers from this study (Table 2 below)shows that there was a significant increase $(\mathrm{p}<0.05)$ in the alanine amino transferase (ALT) activity of the rats in both SA Day-14 and
SA Day-1 sodium arsenite $(2.5 \mathrm{mg} / \mathrm{Kg})$ treated groups, compared with the control group. Although the pre-treated group shows a nonsignificant reversal in the increased ALT level with EETP $(200 \mathrm{mg} / \mathrm{kg})$ administration, this was however still significantly higher $(\mathrm{P}<0.05)$ when compared with the control group. Although there was no significant variation in the activities of AST and GGT, the inductive capacity of sodium arsenite on these hepatic enzymes was shown in the sodium arsenite-induced animal groups, which were also reversed in the Tridax procumbens co- 
treated groups. AST is an enzyme that helps metabolize alanine, an amino acid.

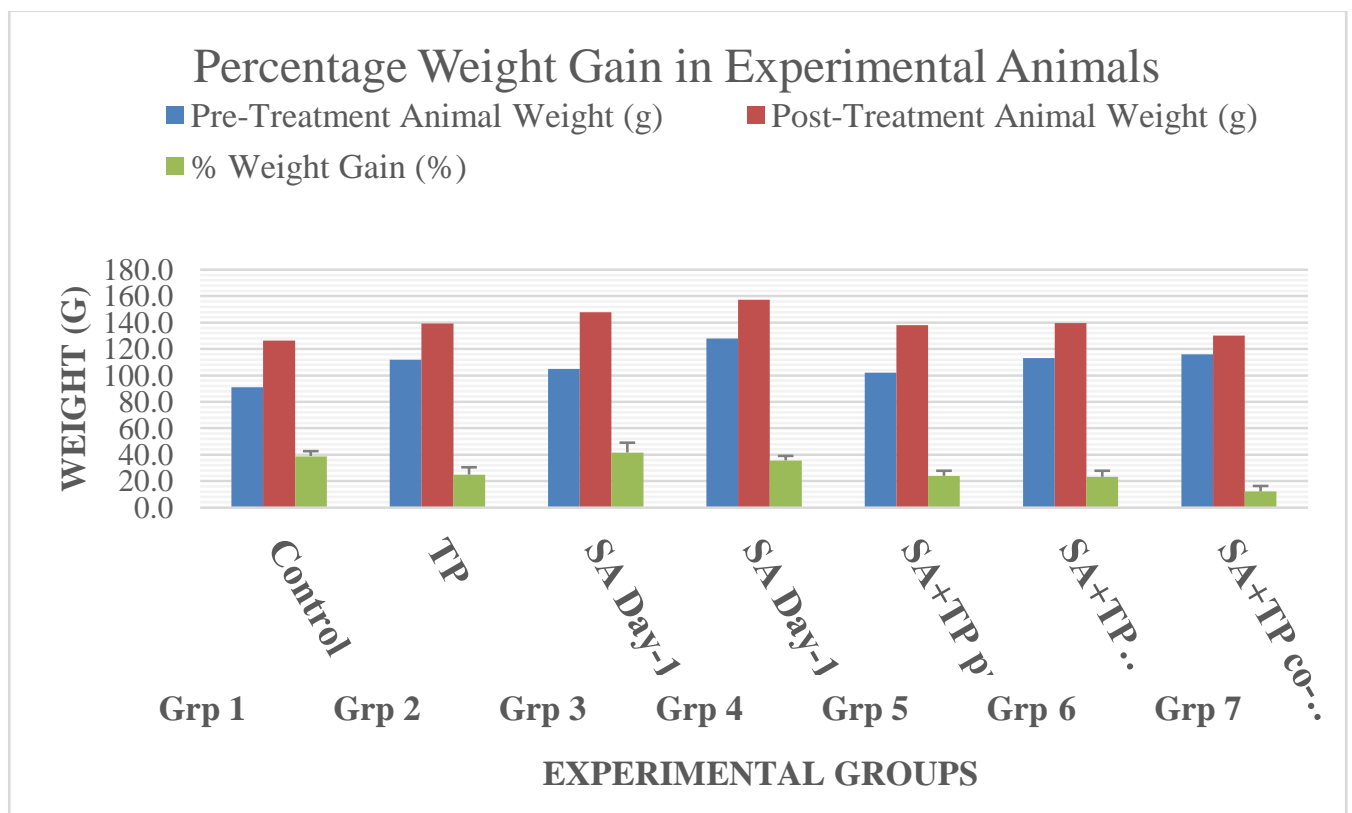

Figure 2: Effect of EETP on \%Weight gain of rats. Values are Mean $\pm \mathrm{SEM}$; * $\mathrm{p}<0.05$ compared to Control.

Table 2: Effect of ethanol extract of Tridax procumbens on liver enzymes activity in sodium arsenite-induced male wistar rats.

\begin{tabular}{c|c|lccc}
\hline \multicolumn{2}{c}{ Experimental Groups } & ALT (U/L) & AST (U/L) & gGT (U/L) & ALP (U/L) \\
\hline Control (D/W) & $\mathbf{1}$ & $8.17 \pm 1.54$ & $9.92 \pm 4.21$ & $5.95 \pm 2.06$ & $35.88 \pm 4.19$ \\
EETP & $\mathbf{2}$ & $15.40 \pm 2.37^{*}$ & $10.50 \pm 0.96$ & $3.57 \pm 0.84$ & $22.63 \pm 1.61^{*}$ \\
SA Day-14 & $\mathbf{3}$ & $18.90 \pm 3.38^{*}$ & $12.60 \pm 1.95$ & $6.90 \pm 0.79$ & $28.15 \pm 3.54$ \\
SA Day-1 & $\mathbf{4}$ & $16.80 \pm 2.85^{*}$ & $12.25 \pm 1.66$ & $7.14 \pm 2.41$ & $26.50 \pm 1.87$ \\
SA + EETP pre-treated & $\mathbf{5}$ & $14.00 \pm 1.46^{*}$ & $8.75 \pm 0.78$ & $3.57 \pm 1.25$ & $27.05 \pm 2.68$ \\
SA + EETP post-treated & $\mathbf{6}$ & $18.55 \pm 2.96^{*}$ & $10.15 \pm 1.02$ & $4.52 \pm 0.79$ & $35.33 \pm 1.61^{\#}$ \\
SA + EETP co-administration & $\mathbf{7}$ & $19.25 \pm 5.44^{*}$ & $11.38 \pm 2.72$ & $5.95 \pm 0.97$ & $24.15 \pm 4.27$ \\
\hline
\end{tabular}

Values are expressed as Mean \pm Standard Error of Mean where $n=5, * \mathrm{p}<0.05$ compared to Control. 
AST is normally present in blood at low levels. An increase in AST levels may indicate liver damage or disease, while a decrease could be as a result of inhibition of certain part of the process of the enzyme function. GGT catalyses the transfer of gamma glutamyl groups from peptides or peptide-like compounds to an acceptor peptide molecule. Although renal tissue has the highest level of GGT, the major source of the enzyme present in serum is of hepatic origin. Elevated levels of GGT are found in association with hepatobiliary and pancreatic disorders, alcoholics [42]. GGT activity has also been shown from previous studies in our laboratory, to be induced by sodium arsenite in laboratory animals ${ }^{[16,17]}$. ALP is an enzyme present in the liver, bile ducts and bone. Alterations in the normal levels of ALP may indicate liver damage or disease, such as a blocked bile duct, or certain bone diseases ${ }^{[43]}$. The data in the table above shows that there was a significant decrease $(p<0.05)$ in the alkaline phosphatase (ALP) activity of the rats in the group treated with EETP $(200 \mathrm{mg} / \mathrm{kg})$ alone, when compared with the control group. This decrease in ALP activity is similar to the observed decrease in ALP activity in both SA Day 14 and SA Day 1 sodium arsenite $(2.5 \mathrm{mg} / \mathrm{Kg})$ treated groups, compared with the control group. However, a significant reverse increase $(\mathrm{p}<0.05)$ in ALP activity was observed in the groups post-treated with EETP $(200 \mathrm{mg} / \mathrm{kg})$, suggesting the acute toxicity effect of sodium arsenite on ALP activity in the other induced animal groups.

Table 3: Effect of ethanol extract of Tridax procumbens on biochemical markers of hepatic and renal function in sodium arsenite-induced male wistar rats

\begin{tabular}{|c|c|c|c|c|c|c|c|}
\hline $\begin{array}{l}\text { Experimental } \\
\text { Groups }\end{array}$ & & $\begin{array}{l}\text { Total Protein } \\
\text { (mg/dL) }\end{array}$ & $\begin{array}{c}\text { Albumin } \\
(\mathbf{m g} / \mathbf{d L})\end{array}$ & $\begin{array}{c}\text { Urea } \\
(\mathrm{mg} / \mathrm{dL})\end{array}$ & $\begin{array}{c}\text { Total } \\
\text { Cholesterol }\end{array}$ & $\begin{array}{c}\text { Total Bilirubin } \\
(\mathrm{mg} / \mathrm{dL})\end{array}$ & $\begin{array}{c}\text { Creatinine } \\
(\mathrm{mg} / \mathrm{dL})\end{array}$ \\
\hline Control (D/W) & 1 & $32.9 \pm 2.40$ & $18.9 \pm 1.10$ & $26.32 \pm 1.72$ & $35.63 \pm 5.67$ & $5.34 \pm 0.56$ & $0.58 \pm 0.16$ \\
\hline EETP & 2 & $27.6 \pm 0.80$ & $13.5 \pm 1.30 *$ & $20.23 \pm 2.30^{*}$ & $21.15 \pm 2.83^{*}$ & $3.73 \pm 0.69$ & $0.92 \pm 0.10$ \\
\hline SA Day-14 & 3 & $30.3 \pm 2.40$ & $15.5 \pm 1.20$ & $21.40 \pm 1.89$ & $26.67 \pm 3.23$ & $4.20 \pm 0.75$ & $1.25 \pm 0.17$ \\
\hline SA Day-1 & 4 & $25.8 \pm 1.90^{*}$ & $13.8 \pm 1.90^{*}$ & $23.16 \pm 0.95$ & $25.59 \pm 2.81$ & $4.63 \pm 0.38$ & $1.02 \pm 0.23$ \\
\hline $\begin{array}{c}\text { SA + EETP pre- } \\
\text { treated }\end{array}$ & 5 & $25.8 \pm 0.40^{*}$ & $13.9 \pm 0.40^{*}$ & $19.44 \pm 0.95^{*}$ & $19.76 \pm 2.75 * *$ & $5.46 \pm 1.13$ & $1.46 \pm 0.11$ \\
\hline $\begin{array}{l}\text { SA + EETP post- } \\
\text { treated }\end{array}$ & 6 & $24.4 \pm 1.60 *$ & $15.4 \pm 0.80$ & $19.46 \pm 1.24 * \#$ & $20.84 \pm 1.63 *$ & $5.49 \pm 0.44$ & $1.19 \pm 0.11$ \\
\hline $\begin{array}{l}\text { SA + EETP co- } \\
\text { administration }\end{array}$ & 7 & $22.7 \pm 1.70$ *\# & $14.6 \pm 1.40^{*}$ & $16.98 \pm 1.33^{* * \#}$ & $23.37 \pm 2.04$ & $3.79 \pm 0.80$ & $0.89 \pm 0.23$ \\
\hline
\end{tabular}

Values are expressed as Mean \pm Standard Error of Mean where $n=5, * p<0.05$ compared to Control.

Biochemical analysis is one way to investigate the biochemical processes going on in vivo. Analysis to determine the liver tissue homogenate concentrations of total protein, albumin, total bilirubin, total cholesterol, and urea were carried out. Albumin is one of several proteins made in the liver and needed by the body to fight infections and to perform other functions such as transportation in the blood. Lower than normal levels of albumin may indicate liver damage or disease. The reduction 
in the tissue levels of albumin when treated with sodium arsenite $2.5 \mathrm{mg} / \mathrm{kg}$ body weight (Table 3 ) in this study is an indication that the treatment inhibited hepatic albumin synthesis, and compromised the immune response of the animals. There was also a combined decrease in the levels of total protein, total cholesterol and urea in the sodium arsenite treated group when compared with the control group. This decrease could either be as a result of a damaged liver architecture leading to leakage of this analyte into the blood stream, or reduction in cholesterol biosynthesis especially by decreasing the 3-hydroxy-3-methyl-glutaryl coenzyme A reductase (HMG CoA reductase) activity, a key enzyme of cholesterol biosynthesis [44] or by increasing the NADPH required for fatty acids and cholesterol synthesis ${ }^{[45]}$, and/or decrease in cholesterol absorption from the intestine, through inhibition of binding with bile acids within the intestine or an increase in bile acids excretion ${ }^{[46]}$. Many of these adverse effects of were not significantly reversed by the administration of Tridax procumbens, except in the restorative (posttreated) treatment group for albumin (see Table 3 ).
Many of these adverse effects of were not significantly reversed by the administration of Tridax procumbens, except in the restorative (posttreated) treatment group for albumin (see Table 3). Rather, as shown by the Tridax procumbens $(200 \mathrm{mg} / \mathrm{Kg}$ ) alone treated groups, the plant under study shows some significant toxicity level. This organ toxicity was shown to be further compounded in the sodium arsenite co-treated groups.

Also, the Liver is known to remove bilirubin, a by-product of breakdown processes of haemoglobin present in red blood cells. During normal function, the liver removes accumulated bilirubin from the blood and excretes it through bile. Many diseases of the liver are accompanied by jaundice, a yellowing of the eyes and skins caused by increased levels of bilirubin in the system. Decrease in total bilirubin observed in the sodium arsenite treated groups (Table 3), compared with the control rats also indicates a compromise in the normal function of the liver in rats, suggesting possible inhibition of this vital physiological process. This was however reversed by the administration of Tridax procumbens both in the pre-treated and post-treated groups.

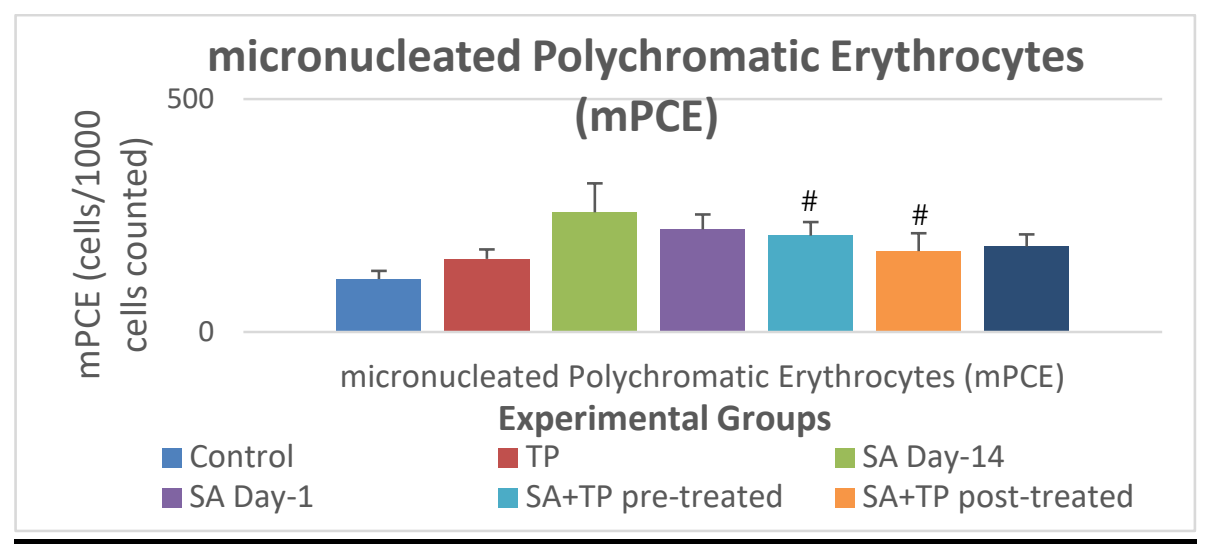

Figure 3: Effect of ethanol extract of Tridax procumbens on micronucleated polychromatic erythrocytes of treated rats. Values are Mean \pm SEM; ${ }^{*} \mathrm{p}<0.05$ compared to Control, \# $\mathrm{p}<0.05$ compared to SA Day-14 and SA Day-1, respectively. 

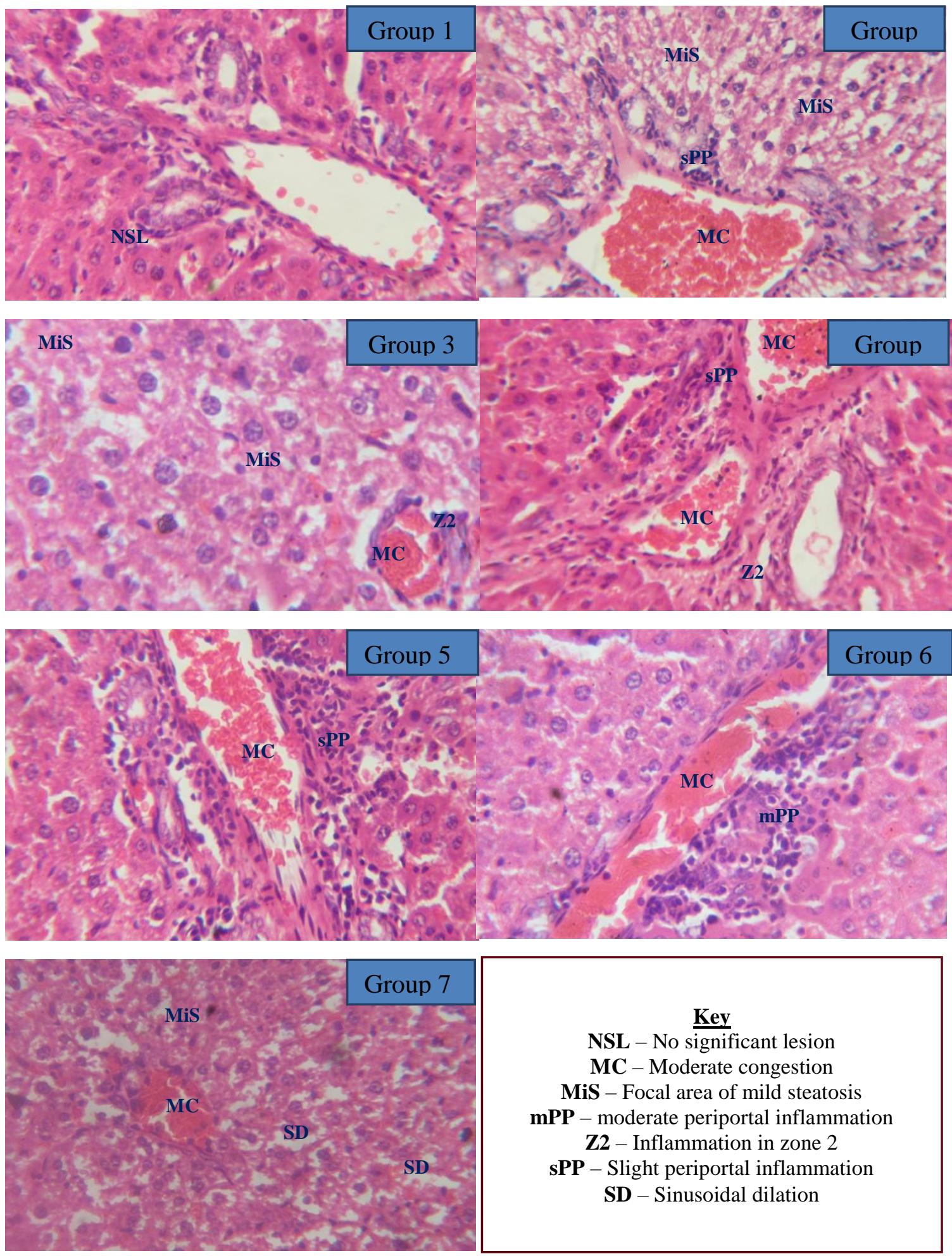

$\underline{\text { Key }}$

NSL - No significant lesion

MC - Moderate congestion

MiS - Focal area of mild steatosis

$\mathbf{m P P}$ - moderate periportal inflammation

$\mathbf{Z 2}$ - Inflammation in zone 2

SPP - Slight periportal inflammation

SD - Sinusoidal dilation

Figure 4: Representative photomicrographs of liver tissue section of rats in each experimental group (H\&E x400).

Group 1 (Control D/W): No significant lesion observed. Group 2 (EETP): moderate congestion of blood vessel and mild steatosis. Group 3 (SA Day-14): moderate congestion and mild staetosis. Group 4 (SA Day-1): moderate congestion, slight periportal and zone 2 inflammations. Group 5 (SA + EETP Pre-treated): moderate congestion and slight periportal inflammation. Group 6 (SA+EETP Post-treated): moderate congestion and periportal inflammation. Group 7 (SA+EETP Co-admin): moderate congestion, mild steatosis and sinusoidal dilation. 

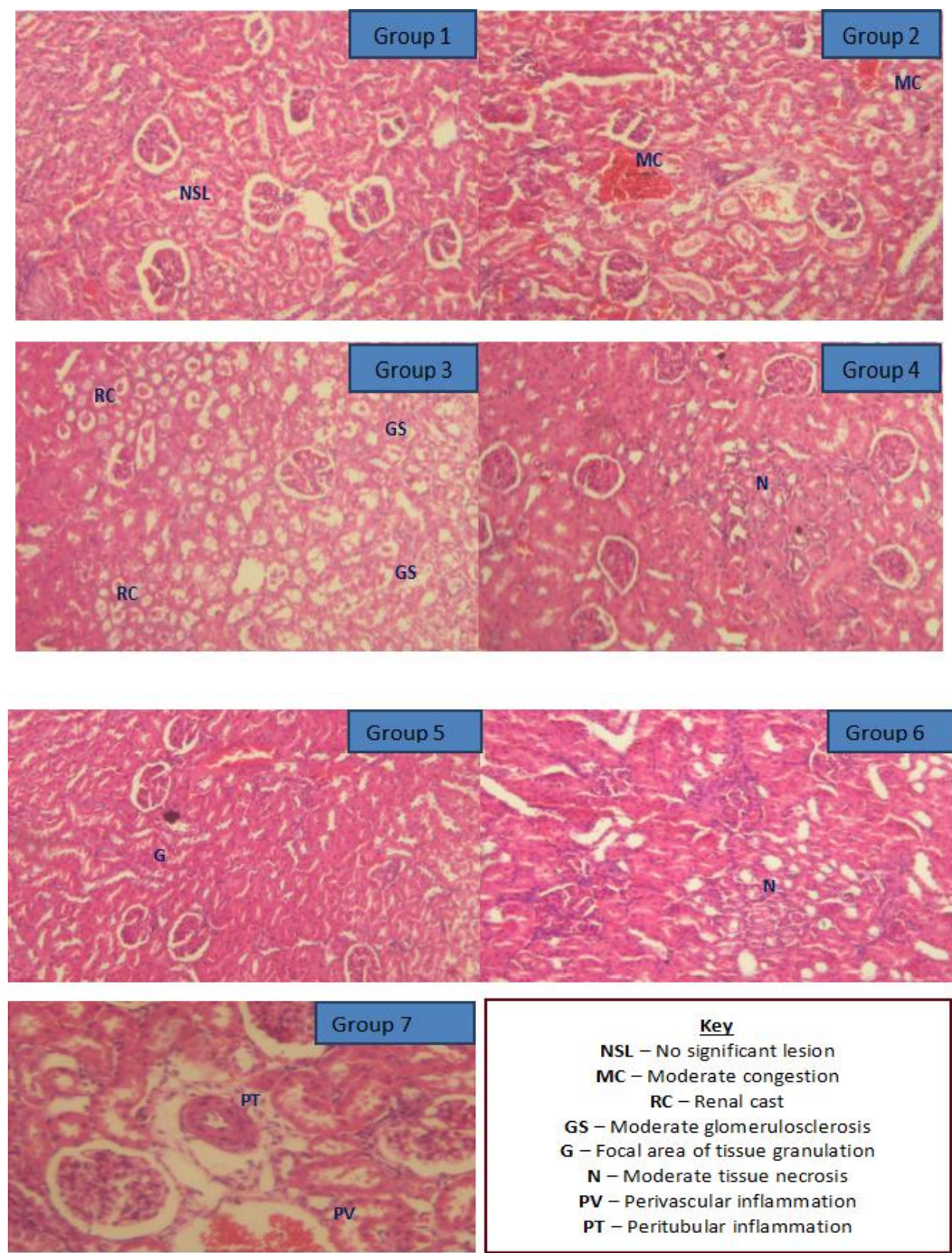

Key

NSL - No significant lesion

MC-Moderate congestion RC - Renal cast

GS - Moderate glomerulosclerosis

G - Focal area of tissue granulation

$\mathbf{N}$ - Moderate tissue necrosis

PV - Perivascular inflammation

PT - Peritubular inflammation

Figure 5: Representative photomicrographs of Kidney tissue section of rats in each experimental group (H\&E x100). Group 1 (Control D/W): No significant lesion observed. Group 2 (EETP): moderate congestion of blood vessel Group 3 (SA Day-14): renal cast and glomerulosclerosis observed. Group 4 (SA Day-1): presence of moderate tissue necrosis. Group 5 (SA + EETP Pre-treated): no significant lesion but focal area of granulation is observed. Group 6 (SA+EETP Post-treated): moderate tissue necrosis observed. Group 7 (SA+EETP Coadmin): presence of peritubular and perivascular inflammation. 
Assessing for serum creatinine level as indicator for nephrotoxicity was similarly carried out in this study. The result from this study shows that EETP possesses a level of toxicity effect, although not as much as sodium arsenite used as toxicant in this work. Like it was observed for the various biochemical analyses using liver tissue homogenate, this was further compounded by administration of Tridax procumbens in the various co-treatment groups. This increase could be due to reduction of the efficiency in the clearance function of the kidney or an increased output of these metabolites by the liver due to an enhanced metabolic rate ${ }^{[47]}$, or even both.

\section{1 mPCE count for assessment of genotoxicity}

Results from this study shows a significant increase $(\mathrm{P}<0.05)$ in the micronucleated polychromatic erythrocytes (mPCE) of both sodium arsenite $(2.5 \mathrm{mg} / \mathrm{Kg})$ treated groups, when compared with the control group, although to a lesser degree in SA Day 1 (Figure 3). Rats in the group treated with EETP $(200 \mathrm{mg} / \mathrm{kg})$ alone, though not statistically significant $(\mathrm{p}<0.05)$, also shows an increase in the mPCE when compared with the control group. There was a nonsignificant $(p<0.05)$ decrease in all the EETP $(200 \mathrm{mg} / \mathrm{kg})$ treated groups, while the post-treated group shows a more beneficial effect with about $21.2 \%$ decrease in mPCE level compared to the pre-treated group with $16.9 \%$ decrease. The anticlastogenic effect of Tridax procumbens as previously reported by Adetutu et al., ${ }^{[48]}$ is also corroborated by the micronucleated polychromatic erythrocyte counts from this study. Similarly, a difference in time of exposure between the SA Day 1 when compared with the SA Day 14 group was demonstrated in this study, although not statistically significantly $(\mathrm{p}<0.05)$.

\subsection{Histopathology of the Liver}

According to Figure 4, the histopathology of the liver section shows moderate congestion of the blood vessels in all the experimental groups, except in the Control (D/W) group where no significant lesion was observed. In addition, the
EETP group shows focal area of mild steatosis and slight periportal inflammation similar to sodium arsenite treated groups (SA DAY-14 and SA Day-1). Although the SA+EETP co treated groups shows a better tissue architecture, indicative of some form of protective effect, however, slight periportal inflammation were observed. This, in support of the biochemical analyses, indicates a marginal line between the beneficial biological effects and toxicity of the ethanol extract of Tridax procumbents on liver tissue.

\subsection{Histopathology of the Kidney}

Histopathology of tissue section of kidney (at x100 magnification) in Figure 5 above shows similar morphology between the Control (D/W) group and EETP alone group, however, moderate congestion was observed in the EETP alone group. Also, significant lesions such as renal casts, glomerulosclerosis, and moderate tissue necrosis were observed in the sodium arsenite treated groups. Significant beneficial effect was of the ethanol extract of Tridax procumbens was observed in the SA+EETP Pre-treated group, except that focal areas of slight tissue granulations were observed. Unlike the pre-treated group, the SA+EETP Post-treated group shows moderate tissue necrosis, while the SA+EETP coadministration group shows both perivascular and peritubular inflammation. The presence of mild lesions, the beneficial effects notwithstanding, corroborates certain degree of toxicity of the ethanol extract of Tridax procumbens (EETP) previously indicated by some of the results of the biochemical analyses in this study.

\section{Conclusion}

As shown by this study and in conformity with previous researches in our laboratories, certain liver enzymes' activity, particularly GGT [16,17] are induced by sodium arsenite in laboratory animals. A level of organ toxicity effect of ethanol extract of Tridax procumbens (linn) (EETP) was 
also shown by the results from this study. This is corroborated by the results of the histopathologicalexaminations. Also, significant difference in time of exposure to sodium arsenite was demonstrated by this study suggesting variation in acute and chronic effect of sodium arsenite induction, with possible physiological restoration in some biological parameters. In exploring scientifically, the beneficial effect of this tropical procumbent herb - Tridax procumbens which has found several use in folkloric medicinal practice, there is to need identify specific therapeutic component, and also to pay attention to possible organ toxicity as side effect of its use.

\section{Acknowledgment}

We like to acknowledge the technical support received from Mr. Ajayi Ifeoluwa of the Pathology department, University College Hospital, Ibadan, during the histopathology aspects of this study.

\section{Competing interest}

The authors have declared that no competing interest exists.

\section{References}

1. Iwu, M.M. Traditional Igbo Medicine: Institute of African Studies, University of Nigeria: Nsukka, Nigeria, 1982; pp104-110.

2. Aruoma, O.I. Extracts as antioxidant prophylactic agents. Inform. 1997, 8: 1236 1242.

3. Cook, N.C., and Samman S. FlavonoidsChemistry, metabolism, cardioprotective effects and dietary sources. $\boldsymbol{J}$ Nutr Biochem, 1996, 7: 66 -76.

4. Ames B.N., Shigenaga, M.K., and Hagen, T.M. Oxidants, antioxidants, and the degenerative disease of aging. Proc Natl Acad Sci USA, 1993, 90: 7915-7922.
5. Ames, B.N., Gold, L.S., and Willet W. The causes and prevention of cancer. Proc Natl Acad Sci USA. 1995, 92:5258-5265.

6. Block, G., Pattersen, B., and Subar, A. Fruit, vegetables and cancer prevention: a review of the epidemiological evidence. Nutr cancer, 1992, 18: 1-29. DOI: $10.1080 / 01635589209514201$

7. Tiwari, A. K. Natural product antioxidants and their therapeutic potential in mitigating peroxidative modification of lipoprotein and atherosclerosis: recent developments. J. Med.

Aromat. Plant Sci., 1999, 21, 730-741.

8. Keaney, Jr. J. F., Simon, D. I., and Freedman, F. Vitamin E and vascular homeostasis: implications for atherosclerosis. $\boldsymbol{F A S E B}$

Journal. 1999, 13 (9):965-976

9. Pietta, P. G. Flavonoids as antioxidants. J. Nat. Prod., 2000, 63, 1035-1042.

10. Halliwell, B. Free radicals, antioxidants, and human disease: curiosity, cause, or consequence? Lancet, 1994,344 (8924), 721724.

11. Wayner, D. D. M., Burton, G. W., Ingold, K. U., Barklay, L. R. C., and Locks, S. J. The relative contributions of vitamin $\mathrm{E}$, urate, ascorbate and proteins to the total peroxyl radical-trapping antioxidant activity of human blood plasma. Biochem. Biophys. Acta. 1987, 924 (3), 408-419.

12. Hodgson, E. Introduction to Toxicology; In: A Textbook of Modern Toxicology. 4th edition. Edited by Hodgson E. Copyright (C) John Wiley \& Sons, Inc, 2010.

13. Biswas, R., Poddar, S., and Mukherjee, A. Investigation on the genotoxic effects of long-term administration of sodium arsenite in bone marrow and testicular cells in vivo using the comet assay. J Environ Pathol Toxicol Oncol, 2007, 26, 29-37.

14. Yousef, M. I., El-Demerdash, F. M., and Radwan, F. M. Sodium arsenite induced biochemical perturbations in rats: 
Ameliorating effect of curcumin. Food Chem Toxicol, 2008, 46, 3506-11. DOI: 10.1016/j.fct.2008.08.031

15. El-Demerdash, F. M., Yousef, M. I. and Radwan, F. M. Ameliorating effect of curcumin on sodium arsenite-induced oxidative damage and lipid peroxidation in different rat organs. Food Chem Toxicol, 2009, 47, 249-54. DOI: 10.1016/j.fct.2008.11.013

16. Odunola, O. A., Uka, E., Akinwumi, K. A., Gbadegesin, M. A., Osifeso, O. O., and Ibegbu, M. D. Exposure of laboratory mice to domestic cooking gas: Implications for toxicity. Int J Environ Res Public Health, 2008, 5, 172-6.

17. Gbadegesin, M. A., Odunola, O. A., Akinwumi, K. A., and Osifeso, O. O. Comparative hepatotoxicity and clastogenicity of sodium arsenite and three petroleum products in experimental swiss albino mice: The modulatory effects of aloe vera gel. Food Chem Toxicol, 2009, 47, 2454-7. DOI: $\underline{10.1016 / \text { j.fct.2009.07.002 }}$

18. Griffon, H., Kiger, J., and Delabesse, P. Comparative analytical study of various commercial shampoos and possible consequences of their use concerning the content of arsenic of the hair. Ann Pharm Fr, 1961, 19, 407-18.

19. Da Costa, E. W. Variation in the toxicity of arsenic compounds to microorganisms and the suppression of the inhibitory effects by phosphate. Appl Microbiol, 1972, 23, 46-53.

20. Shariatpanahi, M., Anderson, A. C., Abdelghani, A. A., Englande, A. J., Hughes, J. and Wilkinson, R. F. Biotransformation of the pesticide sodium arsenate. J Environ Sci Health B, 1981, 16, 35-47. DOI: 10.1080/03601238109372237

21. Chen, Z., Cai, Y., Solo-Gabriele, H., Snyder, G. H., and Cisar, J. L. Interactions of arsenic and the dissolved substances derived from turf soils. Environ Sci Technol, 2006, 40, 4659-65.
22. Chouchane, S., and Snow, E. T. In vitro effect of arsenical compounds on glutathionerelated enzymes. Chem Res Toxicol, 2001, 14, 517-22.

23. Lee, T.C., and Ho, I. C. Differential cytotoxic effects of arsenic on human and animal cells. Environ Health Perspect, 1994, 102 Suppl 3, 101-5.

24. Ramos, O., Carrizales, L., Yanez, L., Mejia, J., Batres, L., Ortiz, D. and Diaz-Barriga, F. Arsenic increased lipid peroxidation in rat tissues by a mechanism independent of glutathione levels. Environ Health Perspect, 1995, 103 Suppl 1, 85-8.

25. Salahdeen, H.M., Yemitan, O.K., and Alade, A.R.A. Effect of Aqueous Leaf Extract of Tridax procumbenson Blood Pressure and Heart Rate in Rats. Afr. J. Blomed. Res., 2004, 7:27- 29.

26. Sahoo, M., and Chand, P.K. In vitro multiplication of a medicinal herb Tridax procumbens L. (Mexican Daisy, coat button): influence of explanting season, growth regulator synergy, culture passage and planting substrate. Phytomorphology, 1998, 48:195 - 206.

27. Ali M., Ravinder E., and Ramachandram R. Phytochemical communication a new flavonoid from the aerial parts of Tridax procumbens. Fitoterapia, 2001, 72:313-315.

28. Pathak, A.K., Saraf, S., and Dixit, V.K. Hepatoprotective activity of Tridax procumbens - Part I. Fitoterapia, 1991, 62, 307-13.

29. Suseela, L., Sarsvathy, A., and Brindha, P. "Pharmacognostic studies on Tridax procumbens L (Asteraceae)". Journal of

Phytological Research, 2002, 15 (2): 141147.

30. Gamboa-Leon, R., Vera-Ku, M., PerazaSanchez, S.R., Ku-Chulim, C., Horta-Baas, A., Rosado-Vallado, M. "Antileishmanial activity of a mixture of Tridax procumbens and Allium sativum in mice.".Parasite, 2014, 
21: 15. PMC 3980668. PMID 24717526. DOI: 10.1051/parasite/2014016

31. Ravikumar, V., Shivashangari, K.S., and Devaki, T. Effect of Tridax procumbenson liver antioxidant defense system during lipopolysaccharide-induced in Dgalactosamine sensitized rats. Mol. Cell Biochem, 2005, 269(1-2):131-6.

32. Vyas, P.S., Tiwari, U., Rastogi B., and Singh P. Immunomodulatory effects of aqueous extract of Tridax procumbens in experimental animals. Journal of Ethnopharmacology, 2004, 92: 113-119.

33. Bhagwat D.A., Killedar, S.G., and Adnaik, R.S. Anti-diabetic activity of leaf extract of Tridax procumbens; International Journal of Green Pharmacy, 2010, 2(2):126-128.

34. Reddipalli H. Anti-hepatotoxic and antioxidant defense potential of Tridax procumbens. Int. J. of Green Pharmacy, 2006, 12 (3):164-169.

35. Diwan P.V., Iravati K., Margaret, I., and Sattur, P.B. Pharmacology and Biochemical Evaluation of Tridax procumbenson inflammation. Indian $\boldsymbol{J}$ of Pharmacology, 1989, 21: 1-7.

36. Marcano L. and Hasenawa D. Analysis of phytochemicals in leaves and seeds. Agronomy Journal. 1991, 83:445-452.

37. Tiwari, P., Kumar, B., Kaur, M., Kaur, G., and Kaur, H. Phytochemical screening and Extraction: A Review. International Pharmaceutical Science, 2011, 1 (1), 98-106.

38. Bongoni, R., Steenbekkers, L.P.A., Verkerk, R., van Boekel, M.A.J.S., Dekker, M. "Studying consumer behaviour related to the quality of food: A case on vegetable preparation affecting sensory and health attributes". Trends in Food Science \&

Technology, 2013, 33 (2): 139-145. DOI: 10.1016/j.tifs.2013.08.004

39. Ikewuchi, C.J., Ikewuchi, C.C., and Igboh, M.N. Chemical profile of Tridax procumbens. Pak J of Nutr., 2009, 8(5): 548-550.
40. Orisakwe, O.E., Hussaini, D.C., and Afonne, O.J. Testicular effects of sub-chronic administration of Hibiscus sabdariffa calyx aqueous extract in rats. Reproductive Toxicology, 2003, 18:295-298. DOI: 10.1016/j.reprotox.2003.11.001

41. Obi, E., Orisakwe, O.E., Asomugha, L.A., and Udemezue, O.O. The hepatotoxic effect of halofantrine in guinea pigs. Indian Journal of Pharmaceutical Sciences, 2004, 36(5):303-305.

42. Gendler S. g-GT. In Kaplan, A. et al. Clinical Chemistry. The C.V. Mosby CO. St Louis. Torronto. Princeton, 1984, pp 1220-1123.

43. Ashade, O.O and Igbokwe, L. Haematological and Biochemical Assessment of Composite Wood Extracts in Albino Rat (Male Wistar Strain). Journal of Natural Sciences Research, 2014, 4(18). ISSN 2224-3186 (Paper) ISSN 2225-0921 (Online). www.iiste.org

44. Sharma, N., Sharma, V.K., and Seo, S.Y. Screening of some medicinal plants for antilipase activity. J. Ethnopharmacol., 2005, 97: 453-456. DOI:10.1016/j.jep.2004.11.009

45. Chi, M.S. Effects of garlic products on lipids metabolism in cholesterol fed rats. In: Proceedings of Society of Experimental Biology and Medicine, 1982, 171: 174-178.

46. Kritchevsky, D., and Dehoff, J.L. Sterol content of seafood as a function of analytical method. J. of Food Sci., 1978, 43 (6), 1786$1787 . \quad$ doi: $\quad \underline{10.1111 / j .1365-}$ 2621.1978.tb07414.x

47. Anofi, O.T.A., Olugbenga, O.O. and Musa, T.Y. Asian Pacific Journal of Tropical Biomedicine, 2012, 2(10): 811-817.

48. Adetutu, A., Owoade, O.A., and Oyekunle O.S. Comparative effects of some medicinal plants on sodium arsenite-induced clastogenicity. Int J Pharm Bio Sci, 2013 4(2): (B) $777-783$. 